\title{
A Comparison of Retrospective Accounts of Childhood Near-Death Experiences with Contemporary Pediatric Near-Death Experience Accounts
}

\author{
William J. Serdahely, Ph.D. \\ Montana State University
}

\begin{abstract}
I compared five childhood near-death experiences (NDEs) reported by adults and another five NDEs reported by minors, in terms of Ring's five NDE stages, Greyson's four NDE components, Moody and Perry's 12 NDE traits, Sabom's 16 general characteristics, and Gallup and Proctor's 10 basic positive experiences. In this combined pool of $47 \mathrm{NDE}$ characteristics (which were interdependent), only two relating to time sense showed significant differences between the adults' retrospective reports of childhood NDEs and the children's contemporary NDE reports, and that number of differences would be expected by chance. This study therefore supports the claims of previous researchers that adults' retrospective reports of childhood NDEs are not embellished or distorted.
\end{abstract}

In reviewing the history of childhood near-death experiences (NDEs), Scott Rogo (1989) noted that children's NDE reports were absent from Raymond Moody's first book on NDEs, Life After Life (1975); and subsequent works by Kenneth Ring (1980), Michael Sabom (1982), Margot Grey (1985), and others were also devoid of pediatric NDEsthat is, NDEs reported by experiencers while they were still children. Rogo noted further that one response to the criticism that NDEs are

Dr. Serdahely is Professor of Health Science at Montana State University. Reprint requests should be addressed to Dr. Serdahely at the Health and Human Development Department, Montana State University, Bozeman, MT 59717. 
culturally conditioned is to study pre-adult experiences: "if the NDEs reported by young children resemble those placed on record by more mature witnesses, perhaps we can reject the cultural expectancy model" (p. 101).

With this kind of rationale in mind, Nancy Bush (1983) published a study of 17 childhood NDEs, 15 of which were retrospective-that is, reported by adults describing NDEs that happened to them when they were children - while the other two were "contemporary accounts" in Bush's terminology. Both contemporary pediatric accounts were in fact transcriptions of the child's experience as told to the mother, who in turn related the experience to the International Association for NearDeath Studies.

After comparing the incidence of NDE features reported by Ring (1980) for adults with those reported in her 17 childhood cases, Bush found childhood and adult NDEs comparable. However, she warned, "In the accounts presented here, it is not possible to determine how much of the affective interpretation is an adult overlay, though the specificity of memory detail in some cases ... suggests that this is not a major issue" (p. 192); and she noted that the retrospective accounts "are necessarily filtered through an adult consciousness" (p. 177).

At about the same time, Melvin Morse (1983) published the first pediatric NDE-that is, a case reported by a minor. Morse elicited a recent NDE account from a 7-year-old girl, interviewing her two weeks after she nearly drowned in a community swimming pool.

A year later, Glen Gabbard and Stuart Twemlow (1984) published three case reports of NDEs in children. Of those three, two were accounts reported by the mothers of the children, and one was an adult reporting retrospectively on her childhood NDE. With regard to the retrospective childhood NDE account, Gabbard and Twemlow found that the 29-year-old respondent was able to describe quite clearly the experience she had had when she was 7: "Although it was approximately 22 years later, she remembered it with vivid clarity" (pp. 157-158).

In his recent book on children's NDEs, Morse claimed: "The mind does not alter the childhood NDE over time, nor does the experiencer change or embellish the story after years of retelling the event" (Morse and Perry, 1990, p. 152). Bush agreed:

There is no indication here that children's experiences are simpler, less detailed, or different in structure from those occurring in adults as described by Raymond Moody (1975), Ring (1980), Sabom (1982), and George Gallup (1982). What may be most remarkable about them 
is that, when compared with the content of adult experiences, they are so unremarkable. (1983, p. 199)

Are these authors correct in their assumption that there is little, if any, difference between adults' retrospective accounts of childhood NDEs and contemporary accounts of pediatric NDEs? Or are the critics correct in saying that adults distort their childhood NDE reports over time and interpret them in light of subsequent acculturation and socialization?

The present study was designed to compare adult retrospective accounts of childhood NDEs with NDE accounts related by minors. The purpose was to determine whether or not the claims of previous investigators can be supported.

\section{Method}

I personally interviewed all the respondents for this study: five adult retrospective NDErs and five contemporary pediatric NDErs.

\section{Subjects}

The five adults, three females and two males, ranged in age from 35 to 67 years old at the time of the interview, and from 3 or 4 years to 17 years of age at the time of the NDE. The five minor respondents, two females and three males, ranged in age from 8.3 to 17.5 years old at the time of the interview, and from 4.25 to 16 years of age at the time of the NDEs.

The difference between age at the time of the NDE and age at the time of the interview averaged 38.3 years (S.D. $=15.5$ years) for the adults, with a range from 22 to 59 years; and this time difference averaged 2.2 years (S.D. $=2.0$ years) for the minors, with a range from 0.2 to 5.5 years.

\section{Statistical Analysis}

Each of the 10 NDEs was scored in five ways. First, each NDE was classified by highest stage reached according to the five NDE stages (peace, bodily separation, entering the darkness, seeing the light, and entering the light) identified by Ring (1980). 
Second, each NDE was categorized according to which of the four components (Cognitive, Affective, Paranormal, and Transcendental) described by Greyson (1983) was most prominent. Because not every respondent had completed Greyson's NDE Scale, the standard instrument for quantifying these four components, these cases were rated by subjective selection of the component that best matched the predominant features of each experience.

Third, each NDE was scored as to the presence or absence of each of $12 \mathrm{NDE}$ traits (sense of being dead, peace/painlessness, out-of-body experience, tunnel experience, people of light, a Being of Light, life review, rising rapidly into the heavens, reluctance to return, different time, different space, and aftereffects) described by Moody and Perry (1988).

Fourth, each NDE was rated as to the presence or absence of each of 16 NDE general characteristics (ineffability, sense of timelessness, sense of reality, sense of death, predominant emotional feelings, separation from physical body, "visualized" details, hearing, attempted communication with others, "thought travel," the return, dark region or void, light, the transcendental environment, encountering others, and life review) described by Sabom (1982).

Fifth, each NDE was rated for presence or absence of 10 basic positive experiences (out-of-body sensation, visual perception, audible human voices, peace and painlessness, light(s), life review, sensation of being in another world, sensing presence of being(s) other than living humans, tunnel experience, and premonitions) listed by Gallup and Proctor (1982).

To compare the group of adults with the group of minors as to their stage according to Ring and their predominant component according to Greyson, and as to the presence of each of Moody's traits, Sabom's general characteristics, and Gallup and Proctor's basic positive experiences, I used Fisher's exact probability test, which is preferred over the chi-squared statistic for small samples (Siegel, 1956).

\section{Results}

As noted above, the time difference between the NDE and the interview for the adult subjects ranged from 22 to 59 years, while that for minor subjects ranged from 0.2 to 5.5 years. That is, all five adult subjects had greater time differences between NDE and interview than did all five minor subjects. That distinction between the two groups was statistically significant; by Fisher's exact probability test, $\mathrm{p}=0.004$. 
A total of 47 Fisher's exact probability tests were performed comparing the retrospective adult accounts with the contemporary minors' accounts in terms of the NDE features described above. These 47 comparisons were not independent of each other, and in fact, some overlapped considerably. For example, a subject's report of leaving the physical body would be counted on five different items: Ring's bodily separation, Greyson's paranormal component, Moody and Perry's outof-body experience, Sabom's separation from physical body, and Gallup and Proctor's out-of-body sensation.

Of the 47 comparisons, only two revealed a difference between the adult and pediatric subjects: Moody and Perry's trait "different time" and Sabom's general characteristic "sense of timelessness," each of which was significant at $p=0.02$ according to Fisher's exact probability test. However, since two comparisons out of $47 \mathrm{might}$ be expected by chance at that level of statistical significance (and perhaps more than two comparisons, given the interdependence of the 47 items), these statistical analyses yielded no evidence of any significant difference between the adult and pediatric groups in the features of their reported NDEs.

\section{Discussion}

The five adults reporting childhood NDEs retrospectively and the five minors reporting contemporary pediatric NDEs differed significantly in the number of years that had elapsed between the NDE and the interview. Yet despite that mean difference of over 36 years, no statistically significant differences could be found between these two groups of childhood NDEs in terms of Ring's five stages, Greyson's four components, Moody and Perry's 12 traits, Sabom's 16 general characteristics, or Gallup and Proctor's 10 basic positive experiences.

In other words, the five adult retrospective accounts of childhood NDEs I investigated and analyzed were not essentially different from the five contemporary pediatric NDE accounts.This study therefore lends support to Bush's suggestion that adult overlay is "not a major issue" in retrospective accounts, Gabbard and Twemlow's claim that their adult respondent could recall her childhood NDE "with vivid clarity," and Morse's assertion that "the mind does not alter the NDE over time." As those earlier researchers concluded, adult retrospective accounts of childhood NDEs appear indistinguishable from contemporary pediatric NDE accounts. 


\section{References}

Bush, N. (1983). The near-death experience in children: Shades of the prison-house reopening. Anabiosis: The Journal of Near-Death Studies, 3, 177-193.

Gabbard, G.O., and Twemlow, S.W. (1984). With the eyes of the mind: An empirical analysis of out-of-body states. New York, NY: Praeger.

Gallup, G., and Proctor, W. (1982). Adventures in immortality: A look beyond the threshold of death. New York, NY: McGraw-Hill.

Grey, M. (1985). Return from death: An exploration of the near-death experience. London, England: Arkana.

Greyson, B. (1983). The near-death experience scale: Construction, reliability, and validity. Journal of Nervous and Mental Disease, 171, 369-375.

Moody, R.A. (1975). Life after life. Covington, GA: Mockingbird Press.

Moody, R.A., and Perry, P. (1988). The light beyond. New York, NY: Bantam.

Morse, M.L. (1983). A near-death experience in a 7-year-old child. American Journal of Diseases of Children, 137, 959-961.

Morse, M.L., and Perry, P. (1990). Closer to the light: Learning from the near-death experiences of children. New York, NY: Villard.

Ring, K. (1980). Life at death: A scientific investigation of the near-death experience. New York, NY: Coward, McCann and Geoghegan.

Rogo, D.S. (1989). The return from silence: A study of near-death experiences. Wellingborough, England: Aquarian Press.

Sabom, M.B. (1982). Recollections of death: A medical investigation. New York, NY: Harper and Row.

Siegel, S. (1956). Nonparametric statistics for the behavioral sciences. New York, NY: McGraw-Hill. 